\title{
Seroprevalence of antibodies to primate erythroparvovirus 1 (B19V) in Australia
}

Helen M. Faddy ${ }^{1,2^{*}}$ (D) Elise C. Gorman ${ }^{1,2}$, Veronica C. Hoad ${ }^{3}$, Francesca D. Frentiu², Sarah Tozer ${ }^{4}$ and R. L. P. Flower ${ }^{1,2}$

\begin{abstract}
Backgroud: Primate erythroparvovirus 1 (B19V) is a globally ubiquitous DNA virus. Infection results in a variety of clinical presentations including erythema infectiosum in children and arthralgia in adults. There is limited understanding of the seroprevalence of B19V antibodies in the Australian population and therefore of populationwide immunity. This study aimed to investigate the seroprevalence of B19V antibodies in an Australian blood donor cohort, along with a cohort from a paediatric population.

Methods: Age/sex/geographical location stratified plasma samples $(n=2221)$ were collected from Australian blood donors. Samples were also sourced from paediatric patients $(n=223)$ in Queensland. All samples were screened for B19V IgG using an indirect- enzyme-linked immunosorbent assay.

Results: Overall, 57.90\% (95\% Cl: 55.94\%-59.85\%) of samples tested positive for B19V IgG, with the national agestandardized seroprevalence of B19V exposure in Australians aged 0 to 79 years estimated to be $54.41 \%$. Increasing age $(p<0.001)$ and state of residence $(p<0.001)$ were independently associated with B19V exposure in blood donors, with the highest rates in donors from Tasmania $(71.88 \%, 95 \% \mathrm{Cl}: 66.95 \%-76.80 \%)$ and donors aged $65-80$ years (78.41\%, 95\% Cl: $74.11 \%-82.71 \%)$. A seroprevalence of 52.04\% (95\% Cl: 47.92\%-56.15\%) was reported in women of child-bearing age (16 to 44 years). Sex was not associated with exposure in blood donors $(p=0.547)$ or in children $(p=0.261)$ screened in this study.

Conclusions: This study highlights a clear association between B19V exposure and increasing age, with over half of the Australian population likely to be immune to this virus. Differences in seroprevalence were also observed in donors residing in different states, with a higher prevalence reported in those from the southern states. The finding is consistent with previous studies, with higher rates observed in countries with a higher latitude. This study provides much needed insight into the prevalence of B19V exposure in the Australian population, which has implications for public health as well as transfusion and transplantation safety in Australia.
\end{abstract}

Keywords: Seroprevalence, Parvovirus B19, Public health, Paediatric, Australia

\section{Background}

Primate erythroparvovirus 1, known as parvovirus B19 or B19 virus (B19V), is a globally ubiquitous DNA virus that may occur more frequently in temperate rather than tropical countries [1, 2]. B19V is a small, non-enveloped, single stranded DNA virus, belonging to the Parvoviridae family $[3,4]$. Three genotypes (genotype 1-3) exist, with genotype 1 the most prevalent world-wide [5]. B19V has a

\footnotetext{
* Correspondence: hfaddy@redcrossblood.org.au

${ }^{1}$ Research and Development, Australian Red Cross Blood Service, Brisbane,

Queensland, Australia

${ }^{2}$ School of Biomedical Sciences, and Institute for Health and Biomedical Innovation,

Queensland University of Technology, Brisbane, Queensland, Australia
}

Full list of author information is available at the end of the article tropism towards human erythroid cells, with the P-blood group antigen serving as the cellular receptor [6]. B19V replicates in bone marrow in erythroid colony forming units, erythroid burst forming units and erythroid precursor cells and has been detected in foetal cardiac, liver and placental cells $[7,8]$. The $\alpha 5 \beta 1$ integrin complex has also been defined as a co-receptor for the entry of B19V into permissive cells, such as erythroid progenitor cells and other non-erythroidal cells [9]. Transmission is usually through the respiratory route, however, vertical transmission, transmission through solid organ or haematopoietic transplantation, and transfusion-transmission have also been documented [10-12].

(c) The Author(s). 2018 Open Access This article is distributed under the terms of the Creative Commons Attribution 4.0 International License (http://creativecommons.org/licenses/by/4.0/), which permits unrestricted use, distribution, and 
Approximately $25 \%$ of infected healthy individuals are asymptomatic [5]. Where symptoms are observed, the most common clinical manifestation in paediatric patients is erythema infectiosum, commonly known as fifth disease or slapped cheek syndrome [13]. B19V has also been shown to play a role in the aetiology of severe anaemia in paediatric patients [14]. Clinical manifestations are observed approximately one week after initial exposure in healthy adults, and can include influenza-like symptoms, rash, polyarthralgia, myalgia, and acute-onset oligoarthritis [15-19]. Vertical transmission of B19V from mother to foetus has been documented, with adverse manifestations including hydrops fetalis, where fluid accumulates in foetal compartments causing complications or death [20]. Clinical manifestations of $\mathrm{B} 19 \mathrm{~V}$ in immunocompromised patients, chronic anaemia, and patients undergoing chemotherapy, are generally atypical [21]. They present with persistent to severe anaemia, fever, lacy skin rash, arthropathy, cardiomyopathy, transient aplastic crisis, and pancytopenia [21]. Transient aplastic crises occurs in those with erythrocyte diseases for example sickle cell disease, thalassaemia and spherocytosis [22]. In those with sickle cell disease it can be life-threatening without prompt treatment [22]. Neurological manifestations, such as encephalopathy and encephalitis, have also been associated with B19V infection [23]. B19V also has the ability to reactivate in immunocompromised patients, which may create difficulties in differentiating between transfusion-transmission and reactivation [24]. The role of B19V in other disease aetiologies, such as other hemotological syndromes, is not well established and there is uncertainty around B19V causation [22].

There is limited knowledge of $\mathrm{B} 19 \mathrm{~V}$ prevalence in the Australian population, which is currently limited to one study, where age specific immunity was estimated in the state of Victoria [2]. That study, conducted in the 1990s, showed the detection of IgG antibodies in $28 \%$ of children aged $0-9$, increasing to $51 \%$ in the next decade of life, and again rising to $78 \%$ in those over the age of 50 [2]. The study is in concordance with previous work from Germany, reporting a rise in exposure from $20 \%$ in children (1-3 years) to $67 \%$ in adolescents (18-19 years), and further increasing to $79 \%$ in the elderly (65-69 years) [25].

There is limited understanding of current seroprevalence of antibodies to $\mathrm{B} 19 \mathrm{~V}$ in the Australian population, and therefore the population-wide immunity status. Given the potential complications arising from B19V infection during pregnancy, the incomplete understanding of $\mathrm{B} 19 \mathrm{~V}$ disease causation and the potential for B19V to be transmitted by blood transfusion and organ transplantation, there are potential implications for both public health as well as transfusion and transplantation safety in Australia. This study aimed to provide a current estimate of B19V seroprevalence in a cohort of Australian blood donors, along with a paediatric population to determine the underlying seroprevalence in Australia and therefore provide information on disease susceptibility in age cohorts.

\section{Methods \\ Study design and population}

This was cross-sectional serosurvey. A sample size of 2200 adult samples was estimated to be suitable using standard procedures [26] with the following assumptions: there is a similar rate of B19V exposure expected in this cohort to that estimated for the Victorian donor population (64\%) [2], a random selection of samples, an absolute precision of $2 \%$ and a $95 \%$ confidence interval (CI). A sub-section of samples were selected from those collected for a separate research project [27], when testing was complete and where an adequate volume remained. Samples were selected (target of 324 per state/territory, totalling 2268 samples) from Queensland (11 to 16 June, 2016), New South Wales (including samples from the Australian Capital Territory; collected: 17 June to 10 September, 2016), Victoria (30 June to 1 July, 2016), Tasmania (29 June to 8 July, 2016), South Australia (29 June to 4 July, 2016), Northern Territory ( 9 August to 16 September, 2016), and Western Australia (19 to 27 August, 2016). Samples were age and sex stratified, with 27 male and 27 female samples targeted for each of the following age groups per state: 16-24, $25-34,35-44,45-54,55-64$ and $\geq 65$ years. Samples $(n=223)$ from paediatric patients (0 to 15 years) in Queensland were also included (between 9 March, 2015 and 16 June, 2016).

\section{Sample collection}

For donor samples, whole blood was collected into $6 \mathrm{~mL}$ dipotassium ethylenediaminetetraacetic acid ( $\mathrm{K}_{2}$ EDTA) sample preparation tubes (BD Vaccutainer - Whole Blood Collection tube with spray-coated $\mathrm{K}_{2}$ EDTA $6 \mathrm{~mL}$, Becton Dickinson, Plymouth, United Kingdom), centrifuged at $1000 \mathrm{~g}$ for $10 \mathrm{~min}$ within $72 \mathrm{~h}$ of collection and stored at $4{ }^{\circ} \mathrm{C}$ temporarily. Plasma was aliquoted into Corning Cryogenic Vials $(5 \mathrm{~mL}$; Corning Incorporated, New York, USA) within 5 days of collection and frozen at $-30{ }^{\circ} \mathrm{C}$ prior to testing. Demographic information (age, sex and state of residence) were obtained for each sample, prior to sample de-identification and assignment of a unique study number. Paediatric serum samples were sourced from patients presenting for non-infectious investigations. Whole blood was collected and processed into serum as per Pathology Queensland 
standard procedures. Basic demographic information, including age and sex, accompanied the samples.

\section{B19V IgG serological testing}

All samples were tested for the presence of B19V IgG with an enzyme-linked immunosorbent assay (ELISA) (Anti-Parvovirus B19 ELISA (IgG) Test; Euroimmun AG, Luebeck, Germany), as per the manufacturer's instructions. This ELISA has a reported specificity (100\%), sensitivity (100\%) and $0 \%$ reporting of cross reactivity (including, but not limited to, against cytomegalovirus, herpes simplex virus 1 , influenza A virus, influenza B virus, measles virus, mumps virus, respiratory syncytial virus, and rubella virus, as well as a parainfluenza virus pool), as determined by in house testing performed by the manufacturer. However, an independent study suggests a slightly lower sensitivity (94.3\%) and specificity (92.3\%) [28]. The antigen used in this assay was a recombinant VP2 protein expressed in eukaryotic cells [28]. Each plate included positive and negative controls, along with a calibrator. An automated pipetting machine (TECAN Freedom Evo; Tecan Group Ltd., Männedorf, Switzerland) was used and absorbance values read using the Synergy H1 Hybrid Multi-Mode Microplate Reader (Biotek, Vermont, USA) at $450 \mathrm{~nm}$ and $630 \mathrm{~nm}$. A ratio of the extinction of the sample over that of the calibrator was calculated, with results interpreted as negative if $<$ 0.8 , borderline if $\geq 0.8$ to $<1.1$, and positive if $\geq 1.1$. All samples were screened once initially, with reactive samples confirmed by a second round of testing. Samples producing discordant results were tested a third time. Samples were considered to be positive for B19V IgG if a reactive result was obtained on two separate screenings. Samples classed as 'borderline' were treated as if they were reactive.

\section{Statistical analyses}

Donor/patient demographic details were recorded in a Microsoft Excel 2010 (Microsoft, Washington, USA) database. The proportion of individuals B19V IgG positive for each age group, sex and state of residencegeographical, residential location, along with overall seroprevalence estimates, with a 95\% CI was calculated using standard methods [29]. National age-standardised seroprevalence estimates were calculated using relevant donor/patient prevalence data with the 2016 census data (2016 census age (in five year groups) by sex) of the Australian population aged $0-79$ used as the standard population [30]. Child-bearing age was defined as those women in the age range from 16 to 44 years, as previously defined [31]. Univariate logistic regression was performed to assess associations between individual independent variables and B19V IgG seropositivity. Variables with $p$-values $<0.1$ in the univariate analyses were included in a multivariate logistic regression model. IBM SPSS Statistics 23 (IBM Centre, NSW, Australia) was used for both the univariate and multivariate logistic regressions. Statistical significance was determined when $p \leq 0.05$.

\section{Results}

Samples from 2221 Australian blood donors and 223 Queensland paediatric samples were screened for the presence of B19V IgG (Table 1). No blood donor reported B19V infection to the Blood Service pre- or post-donation and BV19 was neither suspected nor investigated in the paediatric population. Overall, $57.90 \%$ (95\% CI: $55.94 \%-59.85 \%$ ) of samples tested positive for B19V IgG, indicating previous exposure (Table 2). The national age-standardised seroprevalence of $\mathrm{B} 19 \mathrm{~V}$ in Australian's aged 0 to 79 years was estimated to be 54.41\% (95\% CI: 54.39\%-54.43\%).

Of the 2221 adult blood donor samples screened, 1360 (61.23\%, 95\% CI: 59.21\%-63.26\%) tested positive for B19V IgG. Donor age $(p<0.001)$ and state of residence $(p<0.001)$ were independently assessed and identified as being associated with B19V exposure (Table 3). Consistent with other studies, the prevalence of B19V IgG seropositivity increased with increasing age among adults, from $51.34 \%$ (95\% CI: $46.27 \%-56.40 \%$ ) in the $16-24$ year age group, to $78.41 \%$ (95\% CI: $74.11 \%-82.71 \%$ ) in donors aged 65-80 years. Of the 565 females of child-bearing age (1644 years), $52.04 \%$ (95\% CI: $47.92 \%-56.15 \%$ ) had B19V IgG. The highest prevalence of $\mathrm{B} 19 \mathrm{~V}$ exposure was in donors from Tasmania (71.88\%, 95\% CI: $66.95 \%-76.80 \%)$ and the lowest in donors from the Northern Territory $(52.56 \%$, 95\% CI: 46.84\%-58.28\%). Sex $(p=0.547)$ was not associated with the presence of B19V IgG. Both donor age group $(p<0.001)$ and state of residence $(p<0.001)$ were associated with B19V IgG positivity in the multivariate analysis; donors in the oldest age group were 3.43 times more likely to have been exposed B19V than those in the youngest age group, while donors in the southern states, including Tasmania, Victoria and South Australia, were $2.22,1.77$, and 1.46 times more likely, respectively, to be seropositive of B19V than donors residing in the Northern Territory (Table 3).

In the paediatric cohort, 55 samples (24.66\%; $95 \% \mathrm{CI}$ : 19.01\%-30.32\%) were positive for B19V IgG (Table 4). Age was associated with $\mathrm{B} 19 \mathrm{~V}$ exposure $(p=0.029)$, with increases from $17.39 \%$ (95\% CI: $8.45 \%-26.33 \%$ ) in the $0-4$ year age group to $36.36 \%$ (95\% CI: $24.76 \%-47.97 \%$ ) in the 10-15 year age group. Children in this older age group were 2.71 times more likely to be B19V IgG positive than those in the youngest age group. Similarly in the adult donor cohort, there was no difference in seropositivity between the sexes $(p=0.261)$. 
Table 1 Age, sex and state breakdown of samples included in study

\begin{tabular}{|c|c|c|c|c|c|c|c|c|c|c|c|}
\hline \multirow[t]{2}{*}{ State } & \multirow[t]{2}{*}{$\mathrm{n}$} & \multicolumn{9}{|c|}{ Age group (years) } & \multirow{2}{*}{$\begin{array}{l}\text { Male } \\
(\%)\end{array}$} \\
\hline & & $0-4$ & $5-9$ & $10-15$ & $16-24$ & $25-34$ & $35-44$ & $45-54$ & $55-64$ & $65-80$ & \\
\hline \multicolumn{12}{|l|}{ BLOOD DONOR } \\
\hline Total & 2221 & - & - & - & 374 & 376 & 376 & 376 & 367 & 352 & $49.93 \%$ \\
\hline New South Wales & 323 & - & - & - & 54 & 54 & 54 & 54 & 54 & 53 & $49.85 \%$ \\
\hline Northern Territory & 293 & - & - & - & 53 & 54 & 54 & 53 & 49 & 30 & $51.19 \%$ \\
\hline Queensland & 323 & - & - & - & 53 & 54 & 54 & 54 & 54 & 54 & $50.15 \%$ \\
\hline South Australia & 321 & - & - & - & 54 & 54 & 54 & 53 & 52 & 54 & $49.84 \%$ \\
\hline Tasmania & 320 & - & - & - & 53 & 54 & 53 & 54 & 52 & 54 & $49.69 \%$ \\
\hline Victoria & 317 & - & - & - & 53 & 52 & 53 & 54 & 52 & 53 & $48.90 \%$ \\
\hline Western Australia & 324 & - & - & - & 54 & 54 & 54 & 54 & 54 & 54 & $50.00 \%$ \\
\hline \multicolumn{12}{|l|}{ PEDIATRIC } \\
\hline Total (Queensland only) & 223 & 69 & 88 & 66 & - & - & - & - & - & - & $49.78 \%$ \\
\hline
\end{tabular}

\section{Discussion}

This is the first, large scale epidemiological study conducted in Australia investigating the seroprevalence of B19V IgG, which will provide an understanding of the Australian-wide immunity to $\mathrm{B} 19 \mathrm{~V}$. The overall seroprevalence of $\mathrm{B} 19 \mathrm{~V}$ in this study was $57.90 \%$, giving an age-standardised seroprevalence of $54.41 \%$ among the Australian population aged 0-79 years. The B19V seroprevalence in the Australian blood donor population was $61.23 \%$, which was similar to reported seroprevalence in blood donors from a number of other countries such as Spain (64.70\%), Brazil (60.00\%) and Japan (67.90\%) [32-34]. The results in blood donors are likely applicable to the general population and therefore this study demonstrates that just under-half of the Australian population is susceptible to B19V. This has possible implications for non-immune obstetric patients, vulnerable patients at increased risk of complications such as those with sickle cell anaemia, as well as for susceptiable transfusion and transplantation recipients.

We observed considerable variation in the rate of previous exposure to $\mathrm{B} 19 \mathrm{~V}$ blood donors residing in different geographical locations in Australia [35]. Interestingly, the highest prevalence of B19V IgG seropositivity was amongst donors from Tasmania, the most southern and temperate state in Australia. The southern states of Victoria and South Australia also had a higher

Table 2 B19V seropositivity in Australian samples (blood donor and paediatric), 2016

\begin{tabular}{llll}
\hline Variable & $n$ & \multicolumn{2}{l}{ B19V lgG seropositive } \\
\cline { 3 - 4 } & & $\mathrm{n}$ & $\%(95 \% \mathrm{Cl})$ \\
\hline Female & 1224 & 698 & $57.03(54.25-59.80)$ \\
Male & 1220 & 717 & $58.77(56.01-61.53)$ \\
Overall & 2444 & 1415 & $57.90(55-94-59.85)$ \\
\hline
\end{tabular}

B19V: Primate erythroparvovirus 1; Cl: Confidence interval seroprevalence rate than those in the north of the country. This is consistent with previous studies that suggest $\mathrm{B} 19 \mathrm{~V}$ infection is more prevalent in temperate climates $[1,2]$. A number of other diseases exhibit similar geographic distributions, with lower seroprevalence rates in tropical areas compared with temperate regions, and studies investigating the mechanisms behind this should be encouraged.

Age was also associated with B19V IgG seropositivity in both the paediatric and donor cohorts, with increasing age linked to higher rates of exposure. This increase in seroprevalence was anticipated and is consistent with previous studies [2, 34, 36-38]. Our results show $17.39 \%$ of Queensland children aged 0-4 years and 21.59\% of those aged $5-10$ years were B19V IgG positive. This estimate is slightly lower than the previously described $28 \%$ of children aged 0-9 in the Victorian study [2], but expected, given the results from this study, which suggest geographical variability in B19V seropositivity in donors with a higher a rate in Victoria. Additional studies in paediatric populations from the other states in Australia, including Victoria, would be of interest. Data comparing the 0-4years and 10-15 year old subjects show an approximate $2 \%$ yearly risk of seroconversion.

Just over half of Australian women of child bearing age had been previously exposed to B19V, suggesting that just under half of Australian women in this category are potentially not immune to $\mathrm{B} 19 \mathrm{~V}$ and therefore remain susceptible. This is particularly of concern for these non-immune women contemplating pregnancy, as B19V may cause hydrops fetalis and other adverse manifestations during gestation [20]. Additional studies on the rate of $\mathrm{B} 19 \mathrm{~V}$ seropositivity in pregnant women would support our observation. Consistent with the geographical differences in B19V seroprevalence described above, women of child-bearing age residing in countries with a higher latitude, including Denmark, Ireland, the 
Table 3 B19V lgG seropositivity in Australian blood donors, 2016

\begin{tabular}{|c|c|c|c|c|c|c|c|}
\hline \multirow[t]{2}{*}{ Variable } & \multirow{2}{*}{$\begin{array}{l}\text { Number } \\
\text { tested }\end{array}$} & \multicolumn{2}{|c|}{ B19V IgG seropositive } & \multicolumn{2}{|c|}{ Univariate logistic regression analysis } & \multicolumn{2}{|c|}{ Multivariate logistic regression analysis } \\
\hline & & $\mathrm{n}$ & $\%(95 \% \mathrm{Cl})$ & OR $(95 \% \mathrm{Cl})$ & $P$ value & OR $(95 \% \mathrm{Cl})$ & $P$ value \\
\hline TOTAL & 2221 & 1360 & $61.23(59.21-63.26)$ & - & - & - & - \\
\hline Sex & & & & & - & & \\
\hline Male & 1109 & 686 & $61.86(59.00-64.72)$ & a & - & - & - \\
\hline Female & 1112 & 674 & $60.61(57.75-63.48)$ & $0.95(0.80-1.13)$ & 0.547 & - & - \\
\hline Age group & & & & & $<0.001$ & & $<0.001$ \\
\hline $16-24$ & 374 & 192 & $51.34(46.27-56.40)$ & a & - & a & - \\
\hline $25-34$ & 376 & 221 & $58.78(53.80-63.75)$ & $1.35(1.01-1.80)$ & 0.041 & $1.36(1.016-1.82)$ & 0.039 \\
\hline $35-44$ & 376 & 202 & $53.72(48.68-58.76)$ & $1.10(0.83-1.47)$ & 0.513 & $1.10(0.83-1.47)$ & 0.503 \\
\hline $45-54$ & 376 & 235 & $62.50(57.61-67.39)$ & $1.58(1.18-2.11)$ & 0.002 & $1.59(1.19-2.13)$ & 0.002 \\
\hline $55-64$ & 367 & 234 & $63.76(58.84-68.68)$ & $1.67(1.24-2.24)$ & 0.001 & $1.68(1.25-2.26)$ & 0.001 \\
\hline $65-80$ & 352 & 276 & 78.41 (74.11-82.71) & $3.44(2.49-4.76)$ & $<0.001$ & $3.43(2.47-4.76)$ & $<0.001$ \\
\hline State/territory & & & & & $<0.001$ & & $<0.001$ \\
\hline New South Wales & 323 & 199 & $61.61(56.31-66.91)$ & $1.45(1.05-2.0)$ & 0.024 & $1.38(1.0-1.91)$ & 0.052 \\
\hline Northern Territory & 293 & 154 & $52.56(46.84-58.28)$ & a & - & $a$ & - \\
\hline Queensland & 323 & 186 & $57.59(52.20-62.97)$ & $1.23(0.89-1.69)$ & 0.211 & $1.16(0.84-1.60)$ & 0.376 \\
\hline South Australia & 321 & 202 & $62.93(57.64-68.21)$ & $1.53(1.11-2.16)$ & 0.009 & $1.46(1.05-2.03)$ & 0.023 \\
\hline Tasmania & 320 & 230 & $71.88(66.95-76.80)$ & $2.31(1.65-3.22)$ & $<0.001$ & $2.22(1.58-3.12)$ & $<0.001$ \\
\hline Victoria & 317 & 213 & $67.19(62.02-72.36)$ & $1.85(1.33-2.57)$ & $<0.001$ & $1.77(1.27-2.47)$ & 0.001 \\
\hline Western Australia & 324 & 176 & $54.32(48.90-59.75)$ & $1.07(0.78-1.48)$ & 0.661 & $1.01(0.73-1.39)$ & 0.951 \\
\hline
\end{tabular}

B19V: Primate erythroparvovirus 1; Cl: Confidence interval; $a$ = reference group

Netherlands and Canada (Montreal), have a higher B19V IgG prevalence, ranging from 63 to $70 \%$ [2, 39-43]; whereas lower prevalence rates were observed in women from tropical regions, including Taiwan (36\%) and Singapore (23\%) [44, 45]. It is not surprising that in Australia, a large country spanning tropical through to temperate climates, the overall seroprevalence rate of $\mathrm{B} 19 \mathrm{~V}$ is in the mid-range of such estimates. However, B19V IgG seropositivity is around 25\% in South African women of childbearing age [46], demonstrating that factors in addition to or other than climate are likely to be

Table 4 B19V lgG seropositivity in Queensland paediatric cohort, 2016

\begin{tabular}{|c|c|c|c|c|c|}
\hline \multirow[t]{2}{*}{ Variable } & \multirow{2}{*}{$\begin{array}{l}\text { Number } \\
\text { tested }\end{array}$} & \multicolumn{2}{|c|}{ B19V IgG seropositive } & \multicolumn{2}{|c|}{ Univariate analysis } \\
\hline & & $n$ & $\%(95 \% \mathrm{Cl})$ & OR $(95 \% \mathrm{Cl})$ & $P$ value \\
\hline TOTAL & 223 & 55 & $24.66(19.01-30.32)$ & - & - \\
\hline \multicolumn{6}{|l|}{ Sex } \\
\hline Male & 111 & 31 & $27.93(19.58-36.27)$ & a & \\
\hline Female & 112 & 24 & 21.43 (13.83-29.03) & $1.42(0.77-2.62)$ & 0.261 \\
\hline Age group & & & & & 0.029 \\
\hline $0-4$ & 69 & 12 & $17.39(8.45-26.33)$ & a & - \\
\hline $5-9$ & 88 & 19 & 21.59 (12.99-30.19) & $1.31(0.59-2.92)$ & 0.512 \\
\hline $10-15$ & 66 & 24 & $36.36(24.76-47.97)$ & $2.71(1.22-6.04)$ & 0.014 \\
\hline
\end{tabular}

B19V: Primate erythroparvovirus 1; Cl: Confidence interval; a $=$ reference group important determinants of virus transmission. Given the differences in prevalence between the states observed here, further studies could investigate the level of B19V immunity in Australian women of child-bearing ages in regions of different latitude to investigate this effect further.

We did not observe a difference in B19V seroprevalence between the sexes in either blood donors or in children, which is consistent with a number of previous studies [1, 2]. However, this conflicts with a German B19V seroprevalence population study, where females were reported to have a higher rate of B19V IgG positivity when compared to males, in both adults and children [25], and also the Taiwanese population, where a similar pattern was observed, albeit lower overall [44]. This could be a reflection of different samples used in the studies or differences between assays used, or, if real, could be a reflection of different behaviours among adults between geographical localities.

Populations with lower protective immunity may represent regions with higher susceptibility to B19V infection. Our data suggest a lower B19V prevalence rate in younger Australians, along with individuals residing in the northern states of Australia. Given that B19V can be transmitted though blood transfusion [12], infection in blood donors may be asymptomatic [47], and the demonstrated increasing seroconversion rate with increasing 
age in these data, transfusion-transmission of B19V is a possible risk. However, symptomatic disease secondary to transfusion-transmission is only reported rarely in the literature and the benefits of blood donor screening may be minimal [12]. Moreover the likelihood of community-acquired B19V infection is far more likely in many circumstances than transfusion-transmission. It is recommended that patient groups at increased risk of infection, regardless of their transfusion status, be monitored for B19V symptoms, given the potential for treatment [12].

This study has a number of limitations. Only one, commercially available, B19V IgG ELISA was used and the serological results were based on repeat reactivity with this one assay. Confirmatory testing with a second ELISA with a different recombinant antigen would provide more confidence in the estimates. Comparing seroprevalence results between different studies using different ELISAs is known to be problematic [48], thus the comparisons discussed above should be interpreted with this in mind. Adult samples were restricted to blood donor samples and the paediatric samples to patients from Queensland only, and thus neither group may be representative of the entire general Australian population. B19V infections exhibit seasonal activity, with peaks in infections in late winter and early spring $[2,25,49]$, and are believed to cycle between 2 years of epidemic activity followed by 2 years of endemicity [2] However, as this was a seroprevalence study looking at prior exposure to this virus rather than acute infection, the timing of sample collection, which was in the Australian winter and early spring of a year with unknown endemicity/epidemicity, is unlikely to impact on B19V IgG antibody status.

\section{Conclusions}

Since the discovery of B19V in Australia in 1975, there has been no national study of its seroprevalence among the general population of Australia. This is the first comprehensive, large scale, national seroprevalence study of $\mathrm{B} 19 \mathrm{~V}$ exposure in the Australian population. The overall seroprevalence of B19V IgG in this study was $57.90 \%$, giving an age-standardised seroprevalence of $54.41 \%$ among Australians aged 079. We show a clear pattern of increasing seroprevalence with increasing age and reveal higher rates of seropositivity in the southern states. Importantly, we demonstrate that just over half of the Australian population is expected to be susceptible to B19V infection if exposed, which has possible implications for the care of non-immune obstetric patients, immunosuppressed patients and those with haematological abnormalities, as well as transfusion and transplantation recipients.

\section{Abbreviations}

B19V: Primate erythroparvovirus 1; Cl: Confidence Interval;

DNA: Deoxyribonucleic acid; ELISA: Enzyme-linked immunosorbent assay; IgG: Immunoglobulin G; $K_{2}$ EDTA: Dipotassium ethylenediaminetetraacetic acid

\section{Acknowledgements}

We would like to thank Australian Red Cross Blood Service staff, especially those in: Donor Services, for sample collection; Manufacturing, for sample transport logistics; T. Tran, E. Hewlett and J. Fryk for assistance with sample selection; G. Shuttleworth, P. Diaz and E. Harris for data acquisition and cleaning; and, H. Chan, A. Keller and C. Seed for assisting with study design and logistics. We also thank S. Bialasiewicz for assisting with the selection of the paediatric samples.

\section{Funding}

Australian governments fund the Australian Red Cross Blood Service to provide blood, blood products and services to the Australian community. The funding body played no role in the design of the study and collection, analysis, and interpretation of data and in writing the manuscript.

\section{Availability of data and materials}

The raw data from this study cannot be shared publicly as ethical approval was not obtained for such a purpose. The datasets used and/or analysed during the current study can be made available from the corresponding author on request.

\section{Authors' contributions}

HMF analysed the data and ECG performed the laboratory testing. HMF and ECG prepared the first draft of the manusciprt. HMF, ECG, VCH, FDF, ST and RLPF contributed to the study conception and design, provided intellectual support in relation to data analysis and in drafting the manuscript, approve the final manuscript and agree to be accountable for all aspects of the work.

\section{Ethics approval and consent to participate}

For blood donor samples, ethical approval was obtained from the Blood Service Human Research Ethics Committee, and blood donors provided written consent for their sample to be used for research purposes. For paediatric samples, ethical approval was obtained from the Children's Health Queensland Ethics Committee. A waiver to consent paediatric individuals was provided, and approved by the aforementioned committee, as samples were sourced from patients presenting for non-infectious investigations such that it was not possible to obtain specific consent for inclusion in this study.

\section{Consent for publication}

Not applicable.

\section{Competing interests}

Francesca D Frentiu is a member of the editorial board (Associate Editor) of this journal. All other authors declare that they have no competing interests.

\section{Publisher's Note}

Springer Nature remains neutral with regard to jurisdictional claims in published maps and institutional affiliations.

\section{Author details \\ ${ }^{1}$ Research and Development, Australian Red Cross Blood Service, Brisbane, Queensland, Australia. ${ }^{2}$ School of Biomedical Sciences, and Institute for Health and Biomedical Innovation, Queensland University of Technology, Brisbane, Queensland, Australia. ${ }^{3}$ Clinical Services and Research, Australian Red Cross Blood Service, Perth, Western Australia, Australia. ${ }^{4}$ Queensland Paediatric Infectious Diseases Laboratory, Centre for Children's Health Research, Brisbane, Queensland, Australia.}

Received: 8 May 2018 Accepted: 19 November 2018 Published online: 07 December 2018

\section{References}

1. Letaief M, Vanham G, Boukef K, Yacoub S, Muylle L, Mertens G. Higher prevalence of parvovirus B19 in Belgian as compared to Tunisian blood 
donors: differential implications for prevention of transfusional transmission. Transfus Sci. 1997;18(4):523-30.

2. Kelly HA, Siebert D, Hammond R, Leydon J, Kiely P, Maskill W. The age-specific prevalence of human parvovirus immunity in Victoria, Australia compared with other parts of the world. Epidemiol Infect. 2000;124(3):449-57.

3. Heegaard ED, Brown KE. Human Parvovirus B19. Clin Microbiol Rev. 2002; 15(3):485-505

4. Conteville LC, Zanella L, Marin MA, Filippis AM, Nogueira RM, Vicente AC, Mendonca MC. Parvovirus B19 1A complete genome from a fatal case in Brazil. Mem Inst Oswaldo Cruz. 2015;110(6):820-1.

5. Blümel J, Burger R, Drosten C, Gröner A, Gürtler L, Heiden M, Hildebrandt M, Jansen B, Montag-Lessing T, Offergeld R, et al. Parvovirus B19 - Revised. Transfus Med Hemother. 2010;37(6):339-50.

6. Brown KE, Anderson SM, Young NS. Erythrocyte P antigen: cellular receptor for B19 parvovirus. Science (New York, NY). 1993;262(5130):114-7.

7. Wan Z, Zhi N, Wong S, Keyvanfar K, Liu D, Raghavachari N, Munson PJ, Su S, Malide D, Kajigaya S, et al. Human parvovirus B19 causes cell cycle arrest of human erythroid progenitors via deregulation of the E2F family of transcription factors. J Clin Invest. 2010;120(10):3530-44.

8. Lamont RF, Sobel J, Vaisbuch E, Kusanovic JP, Mazaki-Tovi S, Kim SK, Uldbjerg N, Romero R. Parvovirus B19 infection in human pregnancy. BJOG Int J Obstet Gynaecol. 2011;1 18(2):175-86.

9. Weigel-Kelley KA, Yoder MC, Srivastava A. a5 31 integrin as a cellular coreceptor for human parvovirus B19: requirement of functional activation of $\beta 1$ integrin for viral entry. Blood. 2003;102(12):3927-33.

10. Doyle $\mathrm{S}$, Corcoran A. The immune response to parvovirus B19 exposure in previously seronegative and seropositive individuals. J Infect Dis. 2006; 194(2):154-8.

11. Eid AJ, Chen SF, ASTIDCoP. Human parvovirus B19 in solid organ transplantation. Am J Transplant. 2013;13(s4):201-5.

12. Juhl $\mathrm{D}$, Hennig H. Parvovirus B19: what is the relevance in transfusion medicine? Front Med (Lausanne). 2018;5:4

13. Chorba T, Coccia P, Holman RC, Tattersall P, Anderson LJ, Sudman J, Young NS, Kurczynski E, Saarinen UM, Moir R, et al. The role of parvovirus B19 in aplastic crisis and erythema Infectiosum (fifth disease). J Infect Dis. 1986:154(3):383-93.

14. Wildig J, Michon P, Siba P, Mellombo M, Ura A, Mueller I, Cossart Y. Parvovirus B19 infection contributes to severe Anemia in young children in Papua New Guinea. J Infect Dis. 2006;194(2):146-53.

15. Anderson MJ, Higgins PG, Davis LR, Willman JS, Jones SE, Kidd IM, Pattison JR, Tyrrell DAJ. Experimental Parvoviral infection in humans. J Infect Dis. 1985; 152(2):257-65.

16. Stahl HD, Seidl B, Hubner B, Altrichter S, Pfeiffer R, Pustowoit B, Liebert UG, Hofmann J, von Salis-Soglio G, Emmrich F. High incidence of parvovirus B19 DNA in synovial tissue of patients with undifferentiated mono- and oligoarthritis. Clin Rheumatol. 2000;19(4):281-6.

17. Woolf AD, Campion GV, Chishick A, et al. Clinical manifestations of human parvovirus b19 in adults. Arch Intern Med. 1989;149(5):1153-6.

18. Reid DM, Reid TM, Brown T, Rennie JA, Eastmond CJ. Human parvovirusassociated arthritis: a clinical and laboratory description. Lancet. 1985; 1(8426):422-5.

19. White DG, Woolf AD, Mortimer PP, Cohen BJ, Blake DR, Bacon PA. Human parvovirus arthropathy. Lancet. 1985;1(8426):419-21.

20. Miller E, Fairley CK, Cohen BJ, Seng C. Immediate and long term outcome of human parvovirus B19 infection in pregnancy. Br J Obstet Gynaecol. 1998;105(2):174-8.

21. Satake M, Hoshi Y, Taira R, Momose SY, Hino S, Tadokoro K. Symptomatic parvovirus B19 infection caused by blood component transfusion. Transfusion. 2011:51(9):1887-95.

22. Qiu J, Soderlund-Venermo M, Young NS. Human Parvoviruses. Clin Microbiol Rev. 2017:30(1):43-113.

23. Douvoyiannis M, Litman N, Goldman DL. Neurologic manifestations associated with parvovirus B19 infection. Clin Infect Dis. 2009;48(12):1713-23.

24. Parsyan A, Candotti D. Human erythrovirus B19 and blood transfusion an update. Transfus Med. 2007;17(4):263-78.

25. Röhrer C, Gärtner B, Sauerbrei A, Böhm S, Hottenträger B, Raab U, Thierfelder W, Wutzler P, Modrow S. Seroprevalence of parvovirus B19 in the German population. Epidemiol Infect. 2008;136(11):1564-75

26. OpenEpi: Open Source Epidemiological Statistics for Public Health. www. openepi.com.
27. Hoad VC, Seed CR, Fryk JJ, Harley R, Flower RLP, Hogema BM, Kiely P, Faddy HM. Hepatitis E virus RNA in Australian blood donors: prevalence and risk assessment Vox Sang. 2017;112(7):614-21.

28. de Ory F, Minquito T, Echevarria JE, Del Mar Mosquera M, Fuertes A. Comparative evaluation of tests for detection of parvovirus B19 $\operatorname{lgG}$ and IgM. APMIS. 2014;122(3):223-9.

29. Mood AM. Introduction to the theory of Statistics; 1950.

30. Australian Bureau of Statistics. https:/guest.censusdata.abs.gov.au/webapi/ jsf/tableView/tableView.xhtml.

31. Pregnancy -info.net. http://www.pregnancy-Infonet/childbirth-history/ childbearing.html.

32. Munoz S, Alonso M, Fernandez M, Munoz J, Garcia-Rodriguez J. Seroprevalence versus Parvovirus B19 in blood donors. Enferm Infecc Microbiol Clin. 1998;16(4):161-2.

33. Slavov SN, Haddad SK, Silva-Pinto AC, Amarilla AA, Alfonso HL, Aquino VH, Covas DT. Molecular and phylogenetic analyses of human parvovirus B19 isolated from Brazilian patients with sickle cell disease and [beta]thalassemia major and healthy blood donors. J Med Virol. 2012;84(10):1652.

34. Ihara T, Furusyo N, Hayashi T, Toyoda K, Murata M, Hayashi J. A populationbased epidemiological survey of human parvovirus B19 infection: a project of the Kyushu and Okinawa population study (KOPS). Arch Virol. 2013:158(12):2465-72

35. Flower R, Gorman E, Hoad V, Frentiu F, Tozer S, Bialasiewicz S, Faddy H. Variation in parvovirus B19 lgG seroprevalence between different states in Australia. In: Australian Society for Microbiology Annual Scientific Meeting 2018. Brisbane; 2018. Available from: http://asmicro-2018. p.asnevents.com. au/days/2018-07-01/abstract/53004.

36. Eis-Hübinger AM, Sasowski U, Brackmann HH. Parvovirus B19 DNA contamination in coagulation factor VIII products. Thromb Haemost. 1999;81(3):476-7.

37. Gay NJ, Hesketh LM, Cohen BJ, Rush M, Bates C, Morgan-Capner P, Miller E. Age specific antibody prevalence to parvovirus B19: how many women are infected in pregnancy? Commun Dis Rep CDR Rev. 1994;4(9):R104-7.

38. Grabarczyk P, Korzeniowska J, Liszewski G, Kalinska A, Sulkowska E, Krug-Janiak M, Kopacz A, Letowska M, Brojer E. Parvovirus B19 DNA testing in polish blood donors, 2004-2010. Przegl Epidemiol. 2012;66(1):7-12.

39. Jensen IP, Thorsen P, Jeune B, Moller BR, Vestergaard BF. An epidemic of parvovirus B19 in a population of 3,596 pregnant women: a study of sociodemographic and medical risk factors. BJOG. 2000;107(5):637-43.

40. Knowles SJ, Grundy K, Cahill I, Cafferkey MT. Susceptibility to infectious rash illness in pregnant women from diverse geographical regions. Commun Dis Public Health. 2004;7(4):344-8.

41. van Gessel PH, Gaytant MA, Vossen AC, Galama JM, Ursem NT, Steegers EA, Wildschut HI. Incidence of parvovirus B19 infection among an unselected population of pregnant women in the Netherlands: a prospective study. Eur J Obstet Gynecol Reprod Biol. 2006;128(1-2):46-9.

42. Gilbert NL, Gyorkos TW, Beliveau C, Rahme E, Muecke C, Soto JC. Seroprevalence of parvovirus B19 infection in daycare educators. Epidemiol Infect. 2005;133(2):299-304.

43. Enders $\mathrm{M}$, Weidner $\mathrm{A}$, Enders $\mathrm{G}$. Current epidemiological aspects of human parvovirus B19 infection during pregnancy and childhood in the western part of Germany. Epidemiol Infect. 2007;135(4):563-9.

44. Lin KH, You SL, Chen CJ, Wang CF, Yang CS, Yamazaki S. Seroepidemiology of human parvovirus B19 in Taiwan. J Med Virol. 1999:57(2):169-73.

45. Matsunaga $Y$, Goh KT, Utagawa E, Muroi N. Low prevalence of antibody to human parvovirus B19 in Singapore. Epidemiol Infect. 1994;113(3):537-40.

46. Schoub BD, Blackburn NK, Johnson S, McAnerney JM. Primary and secondary infection with human parvovirus B19 in pregnant women in South Africa. S Afr Med J. 1993:83(7):505-6.

47. Ke L, He M, Li C, Liu Y, Gao L, Yao F, Li J, Bi X, Lv Y, Wang J, et al. The prevalence of human parvovirus B19 DNA and antibodies in blood donors from four Chinese blood centers. Transfusion. 2011;51(9):1909-18.

48. Shrestha AC, Flower RL, Seed CR, Stramer SL, Faddy HM. A comparative study of assay performance of commercial hepatitis $E$ virus enzyme-linked immunosorbent assay kits in Australian blood donor samples. J Blood Transfus. 2016;2016:9647675

49. Tsujimura M, Matsushita K, Shiraki H, Sato H, Okochi K, Maeda Y. Human parvovirus B19 infection in blood donors. Vox Sang. 1995;69(3):206-12. 